\title{
O SUPREMO TRIBUNAL FEDERAL E O DESENVOLVIMENTO NACIONAL
}

\author{
THE BRAZILIAN SUPREME COURT AND THE NATIONAL DEVELOPMENT
}

\author{
iD Márcia Haydée Carvalho \\ Doutora em Direito do Estado \\ Universidade Federal do Maranhão. São Luís/MA - Brasil \\ marciahaydee@uol.com.br
}

\begin{abstract}
Resumo: Tem-se como objetivo analisar em que medida o Supremo Tribunal Federal - STF vem levando em conta o desenvolvimento nacional, ao apreciar grandes decisões políticas do Estado brasileiro, quando esse objetivo fundamental colide com outros interesses constitucionalmente protegidos, no período pós-Constituição de 1988. Como resultado, obtevese que a Corte Suprema realizou implícita e corretamente a ponderação entre o desenvolvimento nacional e o outro bem colidente em um dos casos estudados, mas não o fez em relação aos outros dois, bem como, em todas essas demandas, não abordou os princípios geopolíticos informadores da sociedade internacional pós-bipolar. Concluiu-se que o Supremo Tribunal precisa utilizar a máxima da proporcionalidade de forma expressa e promover a oitiva prévia de especialistas em geopolítica, em audiências públicas, para resolver tais lides. Utilizou-se como método de procedimento o estudo de casos, como método de abordagem o descritivoexploratório e como técnicas de pesquisa a revisão bibliográfica e jurisprudencial.
\end{abstract}

Palavras-chave: Supremo Tribunal Federal. Desenvolvimento Nacional. Geopolítica.

Abstract: Our objective is analyze to what extent the Brazilian Supreme Court taking into account the national development when evaluate the great politic decisions of the Brazilian State in that this fundamental goal collides with others constitutionally protected interests in period post-Constitution of 1988. The result was that in one of the case studies the Supreme Court executed an implicitly weighting between the national development and other colliding interests, but the Court didn't do the same in relation to the other two cases and in all these demands didn't treat of geopolitical principles that inform post-bipolar international society. We concluded which the Supreme Court needs to use the proportionality maxim and realize public audiences to hear specialists in geopolitics to judge these types of cases. We used as procedure method the case study, as approach method the descriptive-exploratory an as research techiniques the bibliografic and documental.

Keywords: Supreme Court of the Brazil. National Development. Geopolitics.

\section{Para citar este artigo \\ ABNT NBR 6023:2018}

CARVALHO, Márcia Haydée. O Supremo Tribunal Federal e o desenvolvimento nacional. Prisma Jurídico, São Paulo, v. 19, n. 2, p. 266-283, jul./dez. 2020. http://doi.org/10.5585/prismaj.v19n2.17341. 


\section{Introdução}

O desenvolvimento nacional é ao mesmo tempo um objetivo fundamental do Estado brasileiro, previsto no Art. $3^{\circ}$, II, da Constituição Federal de 1988 e um direito fundamental, por força do disposto no Art. $5^{\circ}, \S 2^{\circ}$, da Lei Fundamental citada.

No período pós-Constituição Federal de 1988, ao apreciar grandes decisões políticas do Estado brasileiro, o Supremo Tribunal Federal teve a oportunidade de decidir colisões do desenvolvimento nacional com outros valores constitucionalmente protegidos. Em casos como estes, entende-se que a solução deve se dar através do uso da máxima da proporcionalidade.

Além disso, considerando que no atual contexto de globalização, o desenvolvimento dos países depende de sua estratégia de inserção internacional, o STF precisa julgar essas lides, interpretando a Constituição à luz dos princípios geopolíticos que informam a sociedade internacional pós-bipolar (Estados Unidos da América - EUA x União das Repúblicas Socialistas Soviéticas - URSS), sem qualquer subordinação aos centros mundiais do poder.

Neste trabalho, tem-se como objetivo geral avaliar em que medida o Supremo Tribunal Federal vem levando em consideração o objetivo fundamental do desenvolvimento nacional em seus julgados sobre grandes decisões políticas do Estado brasileiro e, como objetivos específicos, verificar se e como o Pretório Excelso tem usado a máxima da proporcionalidade e os princípios geopolíticos da sociedade internacional pós-bipolar para julgar essas importantes lides.

O método de procedimento utilizado foi o estudo de casos julgados pelo Supremo Tribunal Federal, identificados a partir de consulta na plataforma disponível no site da Suprema Corte. Quanto ao método de abordagem, escolheu-se o descritivo exploratório. As técnicas de pesquisa foram a revisão bibliográfica e a jurisprudencial.

O artigo se encontra dividido em seis capítulos: o primeiro esta introdução; o segundo, onde se apresenta o conceito de geopolítica e se aborda a geopolítica brasileira no contexto da geopolítica mundial; a seguir, o tema discutido é o desenvolvimento nacional, discorrendo-se sobre ele como objetivo fundamental e como direito fundamental; no quarto capítulo, enfrentase a temática da interpretação das normas constitucionais e, mais particularmente, das normas de direito fundamental, tomando a teoria de Alexy (2008) como marco teórico para a interpretação da colisão entre esses direitos; no quinto capítulo, faz-se um estudo de três relevantes casos julgados pelo Supremo Tribunal Federal com vistas a atender os objetivos deste trabalho; o último capítulo é dedicado à conclusão do artigo. 


\section{Geopolítica brasileira}

Mattos (2002, p. 18) conceitua Geopolítica como "produto da interação dinâmica dos três fatores: Política, Geografia e História, conduzindo a uma prospectiva dos acontecimentos do Estado"

Segundo Pereira (2018), a geopolítica ajuda a construir o futuro de uma nação, porquanto apresenta uma atitude ativa e criativa, ao esboçar o seu povir desejado, a partir do qual difunde uma cultura de inovação orientadora do planejamento nacional que, normalmente, se realiza em condições de incerteza, a qual deixa de ser uma ameaça.

O geopolítico e planejador não ignora a incerteza, mas busca reduzi-la ao máximo, ao aplicar um método para conviver e aprender a lidar com ela (PEREIRA, 2018).

Pereira (2018) sintetiza esse pensamento, afirmando que a geopolítica parte do pressuposto de que, respeitados os objetivos nacionais permanentes explicitados na Constituição de qualquer país, a melhor forma de predizer o futuro é inventá-lo pela montagem de um cenário querido, depois de uma análise criteriosa das conjunturas internacional e nacional de uma determinada nação.

Apesar das mudanças ocorridas no mundo decorrentes da globalização1, "a Geopolítica continua viva e seu estudo indispensável ao estadista e aos formuladores de Políticas" (MATTOS, 2002, p.34).

Nos últimos dois séculos, a sociedade mundial esteve alicerçada na figura do EstadoNação, cujos suportes fundamentais foram o respeito aos princípios constitucionais da soberania e autodeterminação dos povos (MATTOS, 2002). A estes se pode adicionar o princípio constitucional da cooperação entre os povos para o progresso da humanidade, vez que o desenvolvimento de uma nação deve trazer prosperidade para as demais, principalmente as de seu entorno.

Com o fim da sociedade internacional pós-bipolar (sociedade sob o domínio de duas grandes potências mundiais, quais sejam, URSS e EUA), verificado em 1989, passou a vigorar a pax-americana, sociedade internacional com apenas os Estados Unidos da América na posição grande líder mundial, agindo para fazer valer sua política externa junto aos demais países do globo. A crise financeira de 2008, por outro lado, significou uma verdadeira revolução copernicana no campo da geopolítica mundial, porquanto trouxe com ela a real possibilidade de desconstrução do mundo americano e sua possível substituição por um mundo multipolar ou

\footnotetext{
Globalização é o processo de aproximação entre as diversas sociedades e nações existentes por todo o mundo, que pode ser caracterizado pela possibilidade de os indivíduos, empresas e nações agirem em âmbito global, o qual apresenta novas facetas, como a terceirização de serviços e tecnologia, em meio à Quarta Revolução Industrial, e o cruzamento das cadeias logísticas de âmbito global, que aproximam os países e limitam os conflitos.
} 
pelo menos por um mundo sem predominância cêntrica dos Estados Unidos e seus tradicionais mecanismos de hegemonia mundial.

"A China se tornou um formidável poder econômico e mesmo militar a ponto de, hodiernamente, disputar espaços estratégicos com a superpotência estadunidense" (BARCELLOS, 2020, p.57). Após o colapso da URSS, a Rússia passou a reformular sua política externa, seja para manter a soberania do país, seja lutando pela estatura de superpotência, seja ainda pela oposição à supremacia mundial dos EUA, fazendo-a pensar que já está em condições de ser uma liderança global (PINTO; OLINIK, 2019, p. 101-102). A Índia ainda não está pronta para assumir o papel de potência mundial, porém o seu caminho nesse sentido já está posto: dependerá dos desdobramentos da disputa entre EUA e China e, sobretudo, de sua capacidade de conseguir realizar mudanças estruturais necessárias para auxiliá-la a construir uma política externa autônoma de potência (BARCELLOS, 2020, p. 67$68)$.

A pandemia do novo coronavírus também fez tremer o tabuleiro geopolítico. Embora seja difícil prever cenários bem definidos de futuro quanto a geopolítica mundial, pode-se reconhecer certas tendências no sentido de que nem todas as mudanças vindouras vão derivar da pandemia em si, senão que vão ser agudizados por ela (BRINGEL, 2020, p. 176)

O Brasil não se encontra entre os países que, após a crise de 2008 e a pandemia do novo coronavírus, estão em condições de, em curto espaço de tempo, dividir com os EUA a liderança mundial quanto ao poderio econômico, político, militar e social.

Pelo contrário, enquanto país de modernidade tardia, o Estado brasileiro apresenta-se desorientado e sem saber para onde caminhar (GÓES, 2018). Apesar disso, deve superar suas limitações histórico e culturais, para construir uma ponte para o futuro, de modo a posicionarse dentre as grandes potências mundiais.

Nesse sentido, baseado em vários autores, é o pensamento de Mattos (2002, p. 95), para quem "o Brasil possui todas as condições geográficas e humanas para se tornar uma grande potência".

Entre as propostas para uma geopolítica brasileira, a fim de que o país alcance esse objetivo, tem-se como as principais as seguintes: a integração territorial e interiorização, inclusive da Amazônia; a estratégia de presença efetiva na Antártica para sua exploração econômica no futuro; o fortalecimento do poder brasileiro no seu entorno estratégico relativo ao Atlântico Sul, com ênfase junto aos países lindeiros da África; e o redimensionamento do Mercosul ou criação de outro processo de integração nacional entre os países da América Latina. 


\section{Desenvolvimento nacional}

No que diz respeito ao desenvolvimento nacional, as visões mais restritas o identificam com o crescimento de seu Produto Nacional Bruto (PNB) ou de sua renda per capita.

Obviamente, não se pode negar que o crescimento econômico é um pré-requisito indispensável para que, no longo prazo, uma sociedade alcance maiores patamares de desenvolvimento (MENDES, 2014).

Contudo, a riqueza não deve ser entendida como um fim em si mesma, desapegada da valorização de cada homem integrante do corpo social, da predominância do interesse nacional sobre qualquer outro interesse, e do compromisso com a democracia.

Entende-se, com base em Sen (2000), que o desenvolvimento tem como fim a melhoria da qualidade de vida das pessoas e a expansão das liberdades que elas desfrutam.

De outra banda, para que seja alcançado, o desenvolvimento requer que se eliminem as principais fontes de privação de liberdade: pobreza e tirania, carência de oportunidades econômicas e destituição social sistemática, negligência dos serviços públicos e intolerância ou interferência excessiva de Estados repressivos (SEN, 2000).

Em outras palavras, a remoção de tais fatores negativos permitem que os indivíduos, tendo aumentadas suas capacidades e possibilidades de escolha, consigam participar como agentes do desenvolvimento. Esses fatores podem ser melhor identificados como a miséria; falta de oportunidade para produção, consumo e troca; não disponibilização de serviços de saúde e educação ou sua oferta com baixa qualidade; inexistência de prestação de seguridade social; baixa longevidade da população e a negação de direitos civis e políticos.

Em síntese, pela teoria de Sen (2000, p. 25), “as liberdades não são apenas os fins primordiais do desenvolvimento, mas também os seus meios principais".

Por esse motivo, o progresso de um país deve ser apurado verificando-se primordialmente se houve aumento das liberdades das pessoas (SEN, 2000). Ou seja, uma nação será desenvolvida não em razão de seus altos índices de renda e de riqueza, mas tanto mais quanto seus cidadãos gozarem de efetiva liberdade (MOTTIN, 2018). Ao mesmo tempo, "a realização do desenvolvimento depende inteiramente da livre condição de agente das pessoas" (SEN, 2000, p. 18) porque, como já se disse, somente dotados de maiores liberdades, os indivíduos terão mais possibilidades de fazer escolhas que contribuam para o processo desenvolvimentista.

Voltando-se os olhos para o Brasil, tem-se que ele é o país mais desigual do mundo no que se refere à distribuição de renda e patrimônio (CALEIRO, 2017). 
Ainda consoante Mendes (2014, p. 5), “o Brasil não se tornará um país desenvolvido se sua renda per capita continuar a crescer à pífia taxa média de 1,4\% ao ano, média observada no período 1985-2012”, a qual sofreu uma redução ainda maior se considerarmos o período 19852017, conforme dados do Banco Mundial (World Bank Group. PIB per cápita a precios actuales Brasil, 2019).

Em outros termos, é necessário que o Estado brasileiro passe a ter elevadas taxas de crescimento nos próximos anos para se desenvolver, combatendo a desigualdade social, melhorando a qualidade da educação pública de nível fundamental e médio, bem como da prestação de saúde pública.

A Constituição Federal de 1988, em seu Art. $3^{\circ}$, II, diz que o desenvolvimento nacional é um objetivo fundamental.

Assim, por estar previsto, de forma expressa, na Lei Maior brasileira vigente, que o desenvolvimento nacional é um objetivo fundamental, não há dúvida de que este é um valor constitucional.

Quanto ao fato de o desenvolvimento nacional ser um direito, parte-se primeiramente dos doutrinadores, como Bobbio (1992), para quem o desenvolvimento, enquanto direito de solidariedade é um direito de terceira geração, assim como o direito à paz internacional, o direito a um meio ambiente protegido e o direito à comunicação.

Analisando com mais cuidado o direito ao desenvolvimento, vê-se que ele está interrelacionado a vários direitos, como o direito à saúde, à educação, à segurança, à seguridade social, e aos direitos políticos, civis e trabalhistas, entre outros direitos fundamentais

Resta clara, portanto, a intenção do constituinte originário de 1988 de contemplar uma noção ampla e holística de desenvolvimento. Este pressupõe, assim, variáveis complexas, não podendo ser confundido com simples crescimento econômico (MOTTIM, 2018).

É com essa abrangência que parte da doutrina brasileira sustenta a existência de um "direito fundamental ao desenvolvimento", ao mesmo individual e coletivo, tendo em vista o disposto no Art. $5^{\circ}, \S 2^{\circ}$, da Constituição Federal de 1988.

A noção do desenvolvimento como direito tem origem ainda no Direito Internacional, considerando o seu reconhecimento por diversos diplomas internacionais como elemento componente da teoria dos direitos humanos, em especial, a Declaração sobre o Direito ao Desenvolvimento, aprovada pela Assembleia Geral das Nações Unidas em 1986 (Resolução n. 41/128) e a Conferência de Viena de Direitos Humanos de 1993.

O direito ao desenvolvimento nacional é direito fundamental, que segundo a classificação de Ramos (2002) pode ser entendido como provido de eficácia gradual. Nesse 
caso, vincula os três poderes constituídos, que nesta direção, não podem se furtar de agir de acordo com suas competências, sempre visando implementar ações e medidas, de ordem jurídica e política que visem o respeito a esse direito.

\section{Interpretação constitucional}

Interpretar normas constitucionais, como a que trata do desenvolvimento nacional, é determinar o sentido e o alcance de seus textos com vistas a sua aplicação a um caso concreto ou a uma hipótese levantada.

Apesar de a Constituição ser interpretada em essência do mesmo modo que as demais leis, o texto constitucional apresenta certas peculiaridades, singularidades ou características que exigem outros métodos de interpretação além da metodologia clássica utilizada para a interpretação das leis em geral: 1) inicialidade, 2) supremacia na ordem jurídica, 3) regulação do fenômeno político, 4) vaguidão e plurivocidade de seu texto, 5) existência de lacunas em seu interior, 6) incorporação de valores morais ao seu conteúdo e 7) inserção de normas de metas sem a indicação da estratégia para atingi-las.

Em razão dessas características, foram desenvolvidos pelos teóricos métodos e princípios específicos de interpretação, particularmente para a interpretação das normas constitucionais, como as de direitos fundamentais.

Entre os autores que desenvolvem uma teoria sobre os direitos fundamentais está Robert Alexy (2008), para quem os princípios constitucionais são mandamentos de otimização, enquanto a ponderação deve resolver a colisão entre eles, os quais podem referir-se tanto a direitos individuais como a bens coletivos constitucionalmente protegidos.

Nesse passo, cabe dizer que a distinção entre princípios e regras é um dos pilares da teoria dos direitos fundamentais de Alexy (CARDOSO, 2013). Com efeito, Alexy (2008) defende que os princípios são normas que ordenam que algo seja realizado na maior medida possível dentro das possibilidades fáticas e jurídicas existentes, enquanto as regras são normas que são sempre satisfeitas ou não satisfeitas.

Para a resolução de uma colisão de direitos fundamentais, por meio da produção da norma de decisão, Alexy (2008) advoga a aplicação do princípio ou máxima da proporcionalidade, o que pode envolver a realização da ponderação entre os interesses colidentes. Mencionado princípio ou máxima, nas precisas palavras de Guerra Filho (1999), impõe a busca de uma solução de compromisso, pela qual se respeita, em um dado caso, mais 
um dos direitos contrapostos, procurando desmerecer o mínimo possível o outro ou os outros direitos colidentes e sem jamais ferir o núcleo essencial deste (s) direito (s).

O princípio da proporcionalidade, que se infere do princípio constitucional do Estado de Direito ou se entende como direito ou garantia decorrente do regime e dos princípios adotados pela Constituição Federal de 1988, conforme disposto em seu Art. $5^{\circ}, \S 2^{\circ}$, apresenta, segundo Alexy (2008), três princípios parciais: o da adequação (pelo qual o meio empregado deve ser o mais apropriado para alcançar o resultado querido), o da necessidade (pelo qual o meio eleito deve ser o menos nocivo para atingir determinado fim), e o da proporcionalidade em sentido estrito ou postulado da ponderação.

A ponderação, correspondente ao terceiro princípio parcial da proporcionalidade, deve se desenvolver em três passos, nos seguintes termos:

\footnotetext{
No primeiro é avaliado o grau de não satisfação ou afetação de um dos princípios. Depois, em um segundo passo, avalia-se a importância da satisfação do princípio colidente. Por fim, em um terceiro passo, deve ser avaliado se a importância da satisfação do princípio colidente justifica a afetação ou a não satisfação do outro princípio (ALEXY, 2008, p. 594)
}

Os princípios parciais da proporcionalidade não são utilizados ao mesmo tempo. Caso seja encontrada uma só resposta ao se empregar a máxima da adequação, o problema está resolvido. Em caso negativo, usa-se o princípio da necessidade. Se ainda assim apresentaremse mais de uma solução para o caso concreto, passa-se ao princípio da proporcionalidade em sentido estrito ou ponderação, que necessariamente traz uma resposta para a questão.

Em repúdio as críticas de que a ponderação não é um modelo aberto a um controle racional, Alexy (2008) admite serem verdadeiras, desde que se queira afirmar com isso que o sopesamento não é um procedimento que conduza, em todos os casos, a um único e inequívoco resultado.

Reagindo às críticas que colocam em dúvida a racionalidade das ponderações de princípios constitucionais, argumenta Borowsky (2013) que tal problema não é um defeito específico do conceito criticado, senão uma propriedade caracterizadora de todo processo de decisão de questões normativas o fato de diferentes pessoas produzirem distintas interpretações.

Canotilho (1998), por seu turno, refuta que a ponderação seja um modelo de abertura para justiça casuísta ou de sentimentos. Para ele o método de balancing não abre mão de uma cuidadosa topografia do conflito nem uma justificação da resolução da colisão através da ponderação.

Cabe dizer também que a geopolítica influencia diretamente o desenvolvimento nacional. Por isso merece toda a atenção de governantes, membros do judiciário e outros 
operadores do direito que lidam com questões relacionadas a ela, sobretudo o Supremo Tribunal Federal, que dá a última palavra sobre grandes decisões políticas do Estado brasileiro.

Assim, a renovação do direito não há de se operar através de uma ordem superior aos Estados nacionais. Em que pese as influências do Direito Internacional, cada povo deve ser livre para construir o seu direito a seu modo.

Daí porque os princípios geopolíticos informadores da sociedade internacional pósbipolar devem ser utilizados na interpretação de questões judiciais envolvendo o desenvolvimento nacional. Esses princípios são, entre outros, a tendência à eliminação do Estado Social (Welfare State), patrocinada pela onda neoliberal; o poder das empresas transnacionais e da tecno-economia, que não conhece limites nem pátria e se expande para qualquer lugar; a abertura mundial do comércio e o fim do caráter dirigente da constituições, com a transferência para as empresas e organizações da sociedade civil da responsabilidade para a administração das questões sociais (GÓES, 2009).

Qualquer pessoa, de direito público ou privado, pode interpretar a Constituição Federal vigente. O governo, os doutrinadores e os indivíduos estão aptos a realizar tal tarefa, mas são os juízes e tribunais, sobretudo o Supremo Tribunal Federal que se apresentam como intérpretes oficiais da Lei Maior.

Os juízes e tribunais desempenham um papel decisivo na interpretação de todo o Direito e, sendo a Constituição a norma suprema, também devem interpretá-la e aplicá-la na resolução dos casos concretos.

Quanto à interpretação/aplicação da Constituição levada a cabo pelo Supremo Tribunal Federal em sede de controle de constitucionalidade concentrado e em sede de controle de constitucionalidade difuso, por ter efeito vinculante, no primeiro caso, e serem dadas em caso de repercussão geral com efeitos erga omnes, no segundo, prevalecem sobre a realizada por qualquer órgão ou poder, possuindo, pois, especial valor no sistema jurídico.

\section{Julgamentos do stf acerca da colisão do desenvolvimento nacional com outros valores constitucionais}

Visando avaliar como o Supremo Tribunal Federal vem julgando a colisão do desenvolvimento nacional com outros valores constitucionais, ao apreciar as grandes decisões políticas do Estado brasileiro, no período pós-Constituição Federal de 1988, resolveu-se realizar um estudo de casos. 
Para tanto, fez-se uma pesquisa no dia 22 de fevereiro de 2020, no sítio oficial do STF, colocando-se alternadamente no link pesquisa de jurisprudência quatro palavras-chave ou expressão, relativos ao período pós-Constituição de 1988: "geopolítica”; “desenvolvimento", "atividades adj econômicas", "empresa adj pública”.

Ao por a palavra-chave "geopolítica" no link pesquisa de jurisprudência do site oficial do Supremo Tribunal Federal, considerando o período posterior à Constituição Federal de 1988, retornaram duas decisões monocráticas, em que tal palavra aparecia apenas no relatório desses julgados, não constando da sua parte decisória. Foram elas: 1) RE / 633548-GO,

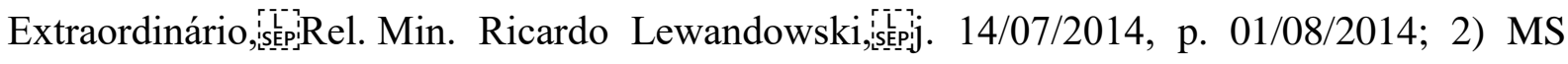

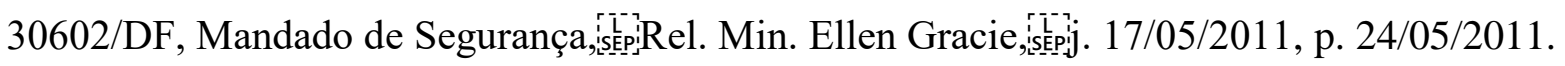

Partiu-se, então, para a colocação da palavra "desenvolvimento", “atividades adj econômicas”, “empresas adj públicas” no link jurisprudência do sítio oficial do STF, quando foram selecionadas, para a elaboração do presente estudo de casos, 3 (três) decisões diretamente relacionadas aos objetivos propostos, quais sejam:

1) Petição 3.388/RR Rel. Min. Carlos Brito, j. 19.03.2009, p. 25.09.2009, relativa à Ação Popular sobre a demarcação da Terra Indígena Raposa Serra do Sol;

2) Referendo na Medida Cautelar na ADI 5624-DF, Tribunal Pleno, Rel. Ricardo Lewandowiski, j. 06/06/2019, p. 29/11/2019, relacionado à desestatização de empresas públicas e sociedades de economia mista que atuam em regime de concorrência; e

3) ADI 3540-MC/DF, sobre a colisão entre o meio ambiente e o desenvolvimento nacional, Rel. Min. Celso de Mello, j. 01/09/2005. p. 03.02.2006.

A seleção dos casos foi realizada, conforme o potencial de relevância para o tema, caso concreto, ementa, relatório e os fundamentos utilizados na decisão.

O primeiro desses julgamentos trata-se de decisão proferida em ação popular (Pet 3.388/RR) em que foi declarada a constitucionalidade e legalidade da Portaria $n^{\circ}$ 534/2005, do Ministro da Justiça, que demarcou as terras indígenas Raposa Serra do Sol, assim como do seu Decreto Presidencial Homologatório.

O STF julgou a demanda parcialmente procedente, em 19 de março de 2009, por maioria de nove votos contra dois. Um dos votos vencidos foi o do Ministro Marco Aurélio, para a anulação da portaria $n^{\circ} 534 / 05$. O outro voto vencido foi o do Ministro Joaquim Barbosa, que entendia, por outro lado, ser totalmente improcedente a ação. 
Contudo, de nenhum dos votos de quaisquer dos Ministros do STF constou qualquer menção ao princípio ou máxima da proporcionalidade difundida por Alexy (1988) no que se refere à resolução da relação tensional entre o direito ao desenvolvimento nacional e o direito dos índios, tendo o primeiro desses direitos sido desprezado ao final pela decisão da maioria do colegiado. Do mesmo modo, nada foi falado sobre geopolítica, sobre a necessidade de interiorização ou de exploração de nossas riquezas de maneira sustentável, de modo que a decisão tomada atendeu, ao final aos interesses dos grandes centros de poder no sentido de que as terras tornadas reservas indígenas permaneçam intocáveis, preservando riquezas que possam no futuro vir a ser exploradas por eles.

Destaca-se que, na referida ação, os povos indígenas envolvidos não foram consultados sobre a demarcação de suas terras, em desatenção à Convenção 169 da Organização Internacional do Trabalho - OIT, e a decisão acabou sendo dada, com base em apenas um laudo antropológico, assinado por um único profissional. Por outro lado, o Supremo Tribunal Federal deu prevalência total a suposto direito dos índios, ao efetuar a demarcação de suas terras de modo contínuo, ampliando enormemente a sua área de abrangência, quando a demarcação poderia ter sido em ilhas.

Com esteio em Ribeiro (2016, p. 233),

\begin{abstract}
Indaga-se se o STF, (...), afastando os dispositivos jurídicos internacionais, apresentou de fato o entendimento mais moderno e humanizado sobre a matéria no julgamento [da Pet 3388/RR], ou, embora tenha deferido a demarcação da terra de forma contínua, retrocedeu a políticas que não conferem autonomia aos povos e comunidades para decidirem sobre suas próprias vidas.
\end{abstract}

Não bastasse isso, do item 4 ao 18 do acórdão, observa-se um verdadeiro ativismo judicial, com a criação de direitos que não constam da Constituição e que estão postos de modo a condicionar decisões futuras do Supremo Tribunal Federal. Desses itens, destacam-se os seguintes: o significado do substantivo "índios" na Constituição Federal abrange índios em processo de aculturação; o marco temporal de ocupação é o da promulgação da Constituição Federal, 05 de outubro de 1988; proibição de desenvolvimento sem ou contra os índios, onde eles estiverem instalados.

$\mathrm{Na}$ verdade, o que a Constituição determina é que se promova um desenvolvimento sustentável nas terras indígenas, que respeite as tradições dos índios, sua cultura e seu modo de reprodução e garanta a eles parte expressiva do que for produzido. Desse modo, tal exploração estaria muito mais adequada com atividades extrativistas, sobretudo o extrativismo vegetal, 
cujo manejo tem menor impacto ambiental do que o mineral. Quanto a esta última atividade, quando em terras indígenas, a própria Constituição Federal determina em seu Art. 231, §3º que:

O aproveitamento dos recursos hídricos, incluídos os potenciais energéticos, a pesquisa e a lavra das riquezas minerais em terras indígenas só podem ser efetivados com autorização do Congresso Nacional, ouvidas as comunidades afetadas, ficandolhes assegurada participação nos resultados da lavra, na forma da lei.

O segundo estudo de caso trazido à baila é o referendo na medida liminar proferida no pedido para permitir a desestatização de empresas públicas e sociedades de economias mistas que exploram atividade econômica em regime de competição com o mercado. Neste estudo de caso, encontravam-se em colisão o objetivo fundamento do desenvolvimento nacional e o princípio fundamental da livre iniciativa. Este princípio pode ser definido, nas palavras de Leite e Santos (2018, p. 126), "como a possibilidade de agir sem influência externa no plano econômico", e se encontra estabelecido no Art. $1^{\circ}$, inciso IV, da Constituição Federal de 1988.

Inicialmente o pedido de medida cautelar em Ação Direta de Inconstitucionalidade 5624-DF foi apreciado monocraticamente, voltado para a suspensão do texto integral da Lei $\mathrm{n}^{\circ}$ 13.303/2016, que regulamenta o Art. $173, \S 1^{\circ}$, da Constituição Federal, alterado pela Emenda Constitucional $n^{\circ}$ 19/1998, ou pelo menos dos seus Arts. $1^{\circ}, 7^{\circ}, 16,17,22$ e 25, aplicando-se interpretação conforme à Constituição para que as demais normas sejam direcionadas, exclusivamente, às empresas públicas e sociedades de economia mista que explorem atividade econômica em sentido estrito, em regime de competição com o mercado, com capacidade de afetar, só no âmbito da União, cerca de 150 (cento e cinquenta) empresas estatais e mais de 550 (quinhentos e cinquenta) mil empregados.

Ao avaliar o referido requerimento, em julgamento de 27/06/2018, publicado em 29/06/2018, o relator do processo, Ministro Lewandowiski, entendeu que se encontrava presente a situação de urgência apontada pelos autores, ao menos em parte, haja vista que, diariamente, vêm sendo noticiadas iniciativas do Governo no sentido de acelerar as privatizações de estatais, como estratégia traçada no Programa de Parcerias de Investimentos (PPI - Lei $\mathrm{n}^{\circ}$ 13.334/2016), com o intuito de ampliar as receitas governamentais. No mérito, deferiu a medida cautelar, ad referendum do plenário, para afirmar que a venda de ações das empresas públicas, sociedades de economia mista ou de suas subsidiárias ou controladas exige prévia autorização legislativa e licitação, sempre que se cuide de alienar o controle acionário. Fundamentou sua decisão em dois pontos. Primeiro, em face do princípio da simetria, já que a Constituição Federal de 1988 exige lei para a criação de empresa pública e sociedade de economia mista, bem como de suas subsidiárias (ver Art. 37, XIX e XX). Em segundo lugar, 
por considerar que permitir a venda direta de ações, em montante suficiente a perder o controle societário de empresa estatal, de maneira a impossibilitar a concorrência pública, poderia atentar contra o texto constitucional, o qual consigna que as alienações serão realizadas "mediante processo de licitação pública que assegure igualdade de condições a todos os concorrentes".

O Ministro Lewandowiski argumentou ainda que, para cada estatal, deve haver uma lei específica, aprovada pelo Legislativo, para vender mais de 50\% das ações de iniciativa privada. Para o referido Ministro, cada estatal precisa de uma lei para ser criada e de outra para ser extinta.

Nessa decisão, o Ministro Relator falou também sobre uma tendência de desestatizações que pode causar danos insanáveis ao Brasil, caso não sejam conduzidas de acordo com a Constituição Federal. Em suas palavras, "há, com efeito, uma crescente vaga de desestatizações que vem tomando corpo em todo os níveis da Federação, a qual, se levada a efeito sem a estrita obediência do que dispõe a Constituição poderá trazer prejuízos irreparáveis ao país”.

Nesse julgamento, apesar de o Ministro Lewandowiski não citar a palavra desenvolvimento, nem geopolítica, demonstrou preocupação com os prejuízos que uma decisão sua em sentido contrário poderia trazer para a economia do Brasil. Ademais, o Ministro Relator conseguiu resolver adequadamente o conflito entre o princípio da livre iniciativa e o interesse público no monopólio estatal de certas atividades econômicas para a promoção do desenvolvimento nacional, por meio da utilização do princípio da máxima da ponderação, ainda que não de forma declarada.

Entretanto, no dia 06 de junho de 2019, o Pleno do Supremo Tribunal Federal referendou parcialmente a medida cautelar susomencionada para atribuir ao Art. 29, caput, da Lei $\mathrm{n}^{\circ}$ 13.303/2016 (a Lei das Estatais) interpretação conforme à Constituição, exigindo autorização legislativa prévia e licitação apenas para a alienação do controle acionário de empresas públicas e sociedades de economia mista (as empresas estatais mãe ou de primeiro grau), considerando que essas exigências não se aplicam à alienação do controle de suas subsidiárias e controladas (as empresas estatais de segundo grau), para as quais impôs tão-somente a observância dos princípios previstos no Art. 37 da Constituição Federal de 1988.

Com efeito, tal posicionamento do Tribunal Pleno tem um potencial lesivo para a economia do país, porque, fazendo prevalecer o princípio da livre iniciativa, deixou o governo federal livre para, sem as amarras do controle legislativo e da necessidade de realizar licitação, desestatizar empresas públicas e sociedades de economia mista subsidiárias e controladas das empresas estatais mães, passando a empresas privadas o controle acionário de empresas estatais 
que, na maioria das vezes, mostram-se estratégicas para o desenvolvimento nacional brasileiro, como as que laboram com petróleo e gás, eletricidade, atividade bancária.

De nenhum dos votos de quaisquer dos Ministros do STF constou qualquer menção ao princípio ou máxima da proporcionalidade de Alexy (2008) no que se refere à resolução da relação tensional entre o objetivo fundamental do desenvolvimento nacional e o princípio fundamental da livre iniciativa, tendo este último prevalecido em relação àquele e atingido o núcleo essencial do objetivo fundamental do desenvolvimento nacional. Igualmente, nada foi falado sobre geopolítica, de modo que a decisão tomada atendeu, ao fim e ao cabo, aos interesses dos grandes centros de poder, voltados para que empresas multinacionais ou transnacionais com sede em seus territórios adquiram ativos no Brasil.

Destaca-se que o caso do Referendo na Medida Cautelar na ADI 5624-DF é totalmente diferente do julgado prolatado na ADI 3273/DF, Tribunal Pleno, Relator: Min. Carlos Brito, j. 16/03/2005, p. 02/03/2007, na qual foi reconhecida a possibilidade de concessão de contratos de petróleo e gás, apesar da existência do monopólio da União previsto no Art. 177 da CF.

Na decisão proferida na ADI 3273, ficou assentado que o petróleo, o gás e outros hidrocarbonetos fluidos são bens de propriedade exclusiva da União, ou seja, são bens monopólio da União. Todavia, a distinção entre atividade e propriedade permite que os resultados da lavra das jazidas de petróleo, de gás natural e de outros hidrocarbonetos fluidos possam ser atribuídos a terceiros pela União sem qualquer ofensa à reserva de monopólio, estabelecida no Art. 177 da Constituição Federal de 1988. Também nessa lide estão em colisão o objetivo fundamental do desenvolvimento nacional e o princípio fundamental da livre iniciativa.

O STF julgou a demanda improcedente, por maioria, vencidos os Ministros Carlos Brito, Marco Aurélio e Joaquim Barbosa, que julgavam a ação parcialmente procedente.

O terceiro estudo de caso objeto de avaliação neste artigo é o julgamento de uma ADI em que estiveram contrapostos o desenvolvimento nacional e o meio ambiente.

Diz respeito à decisão de Medida Cautelar na Ação Direta de Inconstitucionalidade ADI 3540 - Distrito Federal, em que o Supremo Tribunal Federal tomou em consideração o desenvolvimento nacional, utilizando o princípio da proporcionalidade, ainda que não de forma expressa, pois reconheceu como mais importante a preservação da integridade do meio ambiente nos espaços territoriais especialmente protegidos, mas com a possibilidade de a administração pública, cumpridas as exigências legais, autorizar, licenciar ou permitir obras e/ou atividades nos espaços territoriais protegidos, desde que respeitada, quanto a estes, a integridade dos atributos justificadores do regime de proteção especial. 
A decisão não foi unânime. Dois dos Ministros, Marco Aurélio e Ayres Britto, consideraram que a medida cautelar deveria ser indeferida por questão formal relativa à questão de mérito, porquanto no entender deles o governo utilizou uma medida provisória, um ato normativo precário, para disciplinar matéria que poderia implicar em prejuízo projetado no tempo, irrecuperável.

À questão ambiental adiciona-se a procura por um equilíbrio entre a preservação e o desenvolvimento continuado, que vinham sendo tratadas como antagônicas, o que era indesejável. Assim, surge o princípio do desenvolvimento sustentável, qual seja, aquele que satisfaz as necessidades do presente sem comprometer a capacidade de as futuras gerações satisfazerem suas próprias necessidades (KÄSSMAYER, 2006).

Finalmente, cabe destacar que também neste último caso estudado os julgadores não o resolveram, interpretando a Constituição à luz dos princípios geopolíticos informadores da sociedade internacional post-bipolar. Isto porque não analisaram as consequências geopolíticas de sua decisão, quando deixaram de mensurar em que medida o aumento do poder político e econômico gerado por uma deliberação mais favorável ao desenvolvimento nacional poderia favorecer uma melhor posição do Brasil no atual contexto internacional.

Tal deficiência, verificada em todos os julgados estudados, poderia ter sido suprida com a realização de audiências públicas antes da apreciação dos casos, com a finalidade de ouvir especialistas em geopolítica de diferentes escolas. A implementação de tal medida deve ser vista como bem-vinda para situações futuras.

\section{Conclusão}

A geopolítica, enquanto produto da interação dinâmica entre geografia, história e política, ajuda a construir o futuro de uma nação posto que, através do planejamento quanto aos espaços que o país deve ocupar, ajuda a afastar as situações de ameaça.

Com o fim da sociedade internacional post-bipolar em 1989, passou a vigorar a paxamericana. A crise financeira de 2008, por outro lado, significou uma verdadeira revolução copernicana no campo da geopolítica mundial, na medida em que trouxe com ela a real possibilidade de desconstrução do mundo americano e sua possível substituição por um mundo multipolar ou pelo menos por um mundo sem predominância cêntrica dos Estados Unidos e seus tradicionais mecanismos de hegemonia mundial, o que deve ser agudizado em razão da pandemia do novo coronavírus.

O Brasil não está entre os países que, após a referida crise, encontram-se em condições de, em curto espaço de tempo, dividir com os EUA a liderança mundial quanto ao poder 
econômico, político, militar e social. Tais países ou bloco de países seriam China, Índia e Rússia.

Pelo contrário, enquanto país de modernidade tardia, apresenta-se desorientado e sem saber para onde deve ir. Apesar disso, deve superar suas limitações históricas e culturais, para construir uma ponte para o futuro, de modo a posicionar-se entre as grandes potências mundiais.

Para retomar o desenvolvimento, um processo de expansão das liberdades reais desfrutadas pelas pessoas, além de ter uma estratégia de inserção internacional, é necessário ainda que se removam as principais fontes de privação de liberdade, entre os quais se destaca a pobreza, a negligência de serviços públicos, a falta de transparência da coisa pública e a insuficiente de assistência aos desamparados.

O Estado brasileiro é um país democrático com governo de sistema multipartidário consensual. Todavia, é um dos lugares mais desiguais do mundo em termos de renda e patrimônio. Além disso, apesar dos avanços havidos no campo da educação e da saúde pública no sentido de ter sido bastante ampliada a sua área de cobertura, de modo a estarem, pelo menos em tese, disponíveis a todos que dela precisem, fato é que a sua qualidade ainda precisa melhorar bastante. Daí porque o Brasil não é um país desenvolvido, mas tão-somente um país emergente.

O desenvolvimento nacional é um objetivo fundamental, conforme definido no Art. $3^{\circ}$, II, da Constituição Federal de 1988. De outra banda, ele é também um direito fundamental de natureza coletiva, por força do disposto no Art. $5^{\circ}, \S 2^{\circ}$, também da Lei Fundamental pátria vigente.

A Constituição, por suas características peculiares, apresenta métodos e princípios específicos de interpretação.

O governo, os doutrinadores e os indivíduos podem realizar a interpretação da Constituição, mas os juízes e tribunais, sobretudo o Supremo Tribunal Federal, apresentam-se como intérpretes oficiais da Lei Maior.

Defende-se que os casos que envolvem grandes decisões políticas nacionais e colisão de direitos fundamentais sejam resolvidos pela aplicação simultânea do princípio da proporcionalidade e do princípio de segundo o qual Constituição deve ser interpretado à luz dos princípios geopolíticos que informam a sociedade internacional post-bipolar.

Foram avaliados três julgamentos do Supremo Tribunal Federal a título de estudo de casos.

A Suprema Corte em um desses casos realizou uma ponderação não explícita entre o desenvolvimento nacional e outros bens coletivos constitucionalmente protegidos, tendo 
tentado realizar a ponderação de direitos em outras duas lides, embora sem sucesso, na medida em que restringiu em demasia o desenvolvimento nacional em benefício do direito colidente, razão pela qual os fundamentos das decisões devem mostrar-se mais claros a fim de evitar eventuais equívocos. Por outro lado, ao resolver tais questões, o STF não interpretou a Constituição à luz dos princípios geopolíticos informadores da sociedade internacional postbipolar, entendendo-se adequado que antes da apreciação de tais casos, o Supremo Tribunal Federal realize audiências públicas para ouvir especialistas em geopolítica.

\section{Referências}

ALEXY, Robert. Teoria dos direitos fundamentais. São Paulo: Malheiros, 2008.

ALMEIDA FILHO, Agassiz. Princípios Fundamentais. In: ALVIM, Eduardo Arruda; LEITE, George Salomão; STRECK, Lênio. (coord.). Curso de direito constitucional. Florianópolis: Tirant lo Blanch, 2018.

BARCELLOS, João Miguel Villas-Bôas. A Índia como terceiro interessado na disputa de poder sino-estadunidense. Revista Conjuntura Global, v. 9. n. 1, p. 53-71, 2020.

BOBBIO, Norberto. A era dos direitos. Trad. Carlos Nelson Coutinho. Rio de Janeiro: Campus, 1992.

BOROWSKY, Martin. Trad. Carlos Bernal Pulido. Las estructuras de los derechos fundamentales. Colombia: Universidad Externado de Colombia, 2003.

BRASIL. MINISTÉRIO DAS MINAS E ENERGIA. Revista da CPRM - Serviço Geológico do Brasil. Superar desafios faz parte da nossa história. 50 anos. 2019.

BRINGEL, Breno. Geopolítica de la pandemia, escalas de la crísis y escenários en disputa. Madrid: Geopolítica(s) Revista de estúdios sobre espacio y poder. Ediciones complutenses. 11 (Especial), p. 173-187, 2020.

CALEIRO, João Pedro. Economia: Brasil é líder mundial em renda concentrada no $1 \%$ mais rico. Revista Exame, p. 14.12.2017. Disponível em:

https://wxame.abril.com.br/economia/brasil-e-lider-mundial-em-renda-concentrada-no-1mais-rico. Acesso em: 21 maio.2019.

CANOTILHO, José Joaquim Gomes. Direito constitucional e teoria da constituição. Coimbra: Almedina, 1998.

CARDOSO, Henrique Ribeiro. Proporcionalidade e argumentação: a teoria de Robert Alexy e seus pressupostos filosóficos. Curitiba: Juruá Editora, 2013.

GÓES, Guilherme Sandoval. El geoderecho y los centros mundiales de poder. 2009. Disponível em: https://pt.slideshare.net/ramoncopa/el-geoderecho-y-los-centros-mundialesde-poder-guilherme-sandoval-ges. Acesso em: 25 de abr. 2019. 
GÓES, Guilherme Sandoval. Geopolítica mundial e America's Grand National Strategy: diálogos epistemológicos indissociáveis. Revista da Escola de Guerra Naval, Rio de Janeiro, v. 24, n. 3, p. 500-542, set./dez. 2018.

GUERRA FILHO, Willis Santiago. O direito como sistema autopoiético. Revista brasileira de filosofia, São Paulo, v.39, n. 163, jul./.set.1991.

KÄSSMAYER, Karin. Desenvolvimento sustentável como princípio fundamental dos direitos humanos. In: PIOVESAN, Flávia (coord.). Direitos humanos. v. 1. Curitiba, Juruá, 2006.

MATTOS, Carlos de Meira. Geopolítica e Modernidade: a geopolítica brasileiro. Rio de Janeiro: Biblioteca do Exército Editora, 2002.

MENDES, Marcos. Por que o Brasil cresce pouco? Desigualdade, democracia e baixo crescimento no país do futuro. Rio de Janeiro: Eselvier, 2014.

MENDES, Gilmar Ferreira; BRANCO, Paulo Gustavo Gonet. Curso de direito constitucional. São Paulo: Saraiva, 2013.

MOTIM, André Luís do Santos. Desenvolvimento em Amartya Sen e a ordem constitucional brasileira. Revista de Direito, Economia e Desenvolvimento Sustentável. Salvador, v.4, n.1, p. 113-134. jan./jun. 2018.

PEREIRA, Carlos Patrício Freitas. Geopolítica mundial e do Brasil no século XXI: o improvável é possível. Rio de Janeiro: Biblioteca do Exército, 2018.

PINTO, José Felipe (orientador); OLIYNYK, Vira. A Rússia um ator indispensável na Geopolítica Mundial. Lisboa: Universidade Lusófona de Humanidades e Tecnologias. Faculdade de Ciências Sociais, Educação e Administração, Dissertação de Mestrado, 2019. Disponível em: recil.grupolusofona.pt/handle/10437/10211. Acesso em: 08. set. 2020.

RAMOS, Paulo Roberto Barbosa. Fundamentos constitucionais do direito à velhice. Florianópolis: Letras Contemporâneas, 2002

RIBEIRO, Thayana Bosi Oliveira. O entendimento do Supremo Tribunal Federal acerca da autodeterminação e da consulta aos povos e comunidades indígenas no julgamento da Pet 3.388/RR. In: CARVALHO, Márcia Haydée Porto de. Pluralismo, democracia e direitos humanos. São Luís, EDUFMA, 2016.

SEN, Armatya. Desenvolvimento como liberdade. São Paulo: Companhia das Letras, 2000.

World Bank Group. PIB per cápita a precios actuales Brasil. Disponível em: https://datos.bancomundial.org/indicador/NY.GDP.PCAP.CD?locations=BR. Acesso em: 01 maio 2019. 